\title{
The New World Neuropsychiatry II
}

\author{
Luis A Pando Orellana* \\ Department of Neuropsychiatrist-Immunologist, Mexico
}

*Corresponding author: Luis A Pando Orellana, Department of NeuropsychiatristImmunologist, Mexico.

Received Date: May 08, 2019

Published Date: May 24, 2019

\section{Short Communication}

There is a specific vinculation with what we are; as evolution and mutations from Homo neanthertalis genome as well as integrated Homo sapiens genome, as the Biome itself since millions of years ago, to the first Hominides, around 50,000 years ago; the mutations that, bacteria, and fages, viral and Priones involved in our proteome as evolutionary agents, have produced. If we could see a photograph of all these evoulionary agents, that travel with us in this tiny planet, a blue dot of a marginal star, within the Milky Way galaxy surrounded by millions of other galaxies in universes; now multiverses.

Certainly the philosophical question to our being (Figure 1) ,finitude, and creativeness arouses: not to mention the replica of this multisystem microuniverse that this machine is able to conceive and think in very big terms as to reproduce in each and every creation, invention or art , the very essence of ourselves. as someone said (Karl Sagan) [1] we are made of stardust but strict Biology it is as in a mirror from the macro (Universes) to the Micro (tens of thousands of neurons); each one with a theme of their own with their own language of signaling to the neighbor, constructing networks in a convergent-divergent neuronal structure. that tries to give us through our senses what is this world all aboutfI G 2,3,4.

Even so, we are far from perfection, because Biology functions decays and degenerates, such as observed in cancers, autoimmune diseases, aging, metabolic errors, and also the external context, the environment meaning: diet, ecological factors, toxicity from outwards to inwards and yes of course expressed in conduct awake and asleep. If we could have a photograph of all these genomes and proteomes circling what we call our body, from the inside and outside, not only from the microscopical point of view but molecular photographs and its signals we would find these schematic versions of ourselves. (Figure 2).

Among these saprophite and pathological beings that accompany us and determine life itself together with our uncertain molecular limits that constitute, skin and organs and systems the definition of man and its behavior, the explanation tends to be and has been philosophical more than biological. So, the New World Neuro- psychiatry Is a continuous growing discipline because we are what we have, and this is our history as human beings with each and every interaction with every single being around us. Our mind is molded by each interaction, from molecules to the Universe. Medicine as such gets more confused at times with so many variables interacting and slowly but definitely understanding better mind-brain structure and not only in CNS structure and functions, but what makes us unique.

Stardust, molecules, waves, molecule language, microorganisms, its products, intracellular structures, energy receptors and generators like the bacteria called mitochondria ,nuclei and DNA- RNA's interactions, proteins that correct, sequences, transcriptases, cell proteome and other edited from different species proteomes, from the atom and waves, that give way to the logical rules of interactions, communications generating a language that continually evolves and transduces information into more complex function: from movement, to language and thought, implicating the rules of logical thought and feeling as well as their disruption through difunctional readings of transcription and other enzymatical errors. We actually are 80 percent viral and bacterial mutations as well as archaic genome from our ancestors (in a 20\%) still evolving Homo sapiens/Neanthertals [2] Alterations, disorders and diseases, each one is supported by inborn and acquired mechanisms of biochemical language and specialized actions through the immunological complex system.

what is recognized as oneself and what is not, what is integrated and what is not, giving nature a chance to adapt o to be suicidal through inflammatory response using cells within cooperative systems and suppressive mechanisms. The anatomopathological common denominator for destruction Inflammatory response that gives way to erase and choose better survival mechanisms [3] (Figure 1). 


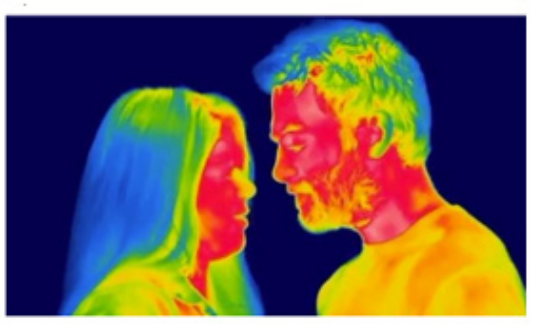

Figure 1: Uv Image of two Human Beings, Lets Imagine that Colors Represent Human Biome. Public Image.

Human beings created by god. But a god, meaning nature in its mirror images are responsible for creativity and violence as well, for ethics and moral, we merely respond to signals generated by this nature, which is not good or bad. The sociological implications tend to be self destructive or hetero distructive as in wars and economical laws of behavior where religions were invented trying to hold impulses creating sin and punishment for whoever destroys similar or complementary beings (LIFE itself in all its manifestations).

Death is not Ceasing to Live; it is mere the Transformation of Energy. (Attributed to Lavoisier).

All neurosciences including psychoanalysis, are devoted to the notion that the world and man are evolving to its objective not to its end. These objective started millions of years ago and particularly in this planet will end giving way to new cycles within this everlasting evolution. Man is not an objective or an end by itself, it is a step in evolution, who tends to individualize his existance, according to" rules" invented by himself to withstand most of all pain: physical or psychological, suffering cancers as such and symbolical ones also destructive as human passions that derive from all of this resumed biological and chemical reactions, that give way to disciplines such as neurosciences that study and try to mold this passions, for a better understanding of societies with its greed, egocentrisms, lust ,war, power over other beings that suffer underneath and finally auto destruction [4].

Searching Peace and Love that Also Come from what Constitutes Us All. Cells and Molecules

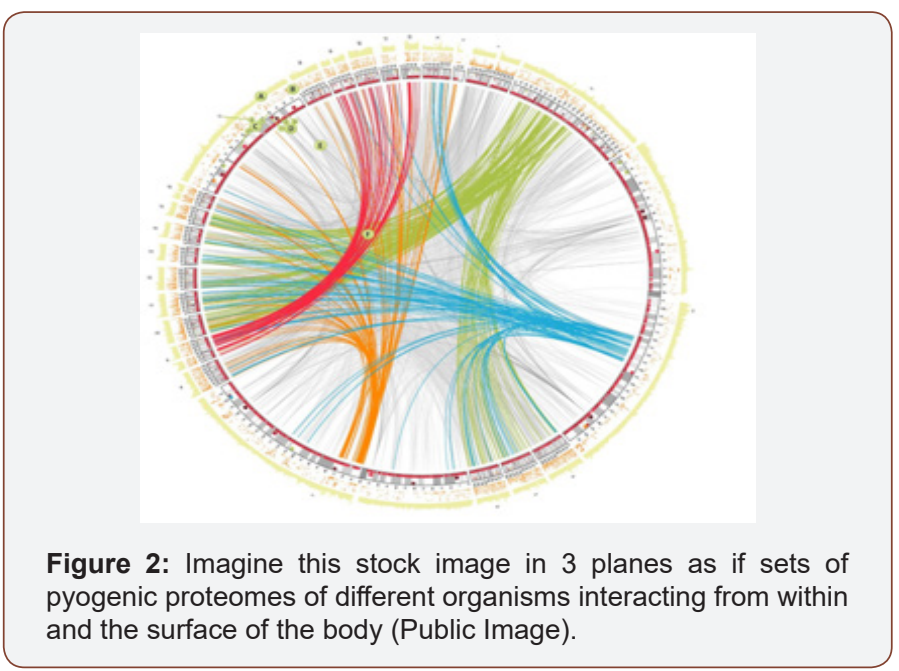

Neuropsychiatry pretends to be the new theological man centered regulation of complex conducts, where laws need to be invented (Legislated; giving name to things from the Latin legislate) for regulation of the eternal overpassing others interests with our own. Such laws are a complex replica of biological contention/ regulation, as well [5] (Figure 2-6).

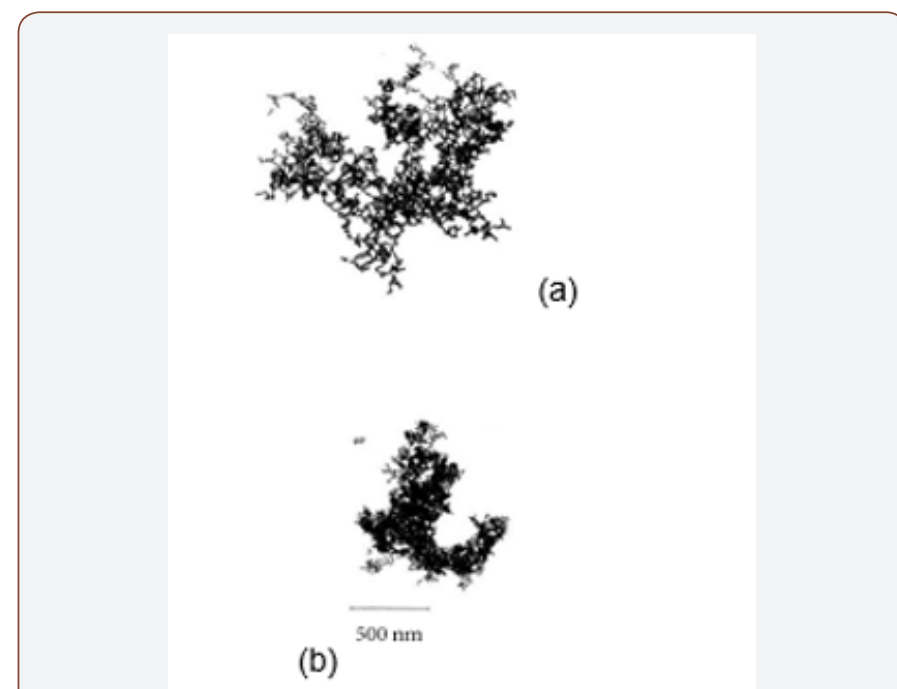

Figure 3: Adapted from Weitzetal. Interaction of molecules. The same image but fractal. Conceiving this tensors and countertenors of bits of information swarming from one side to another.
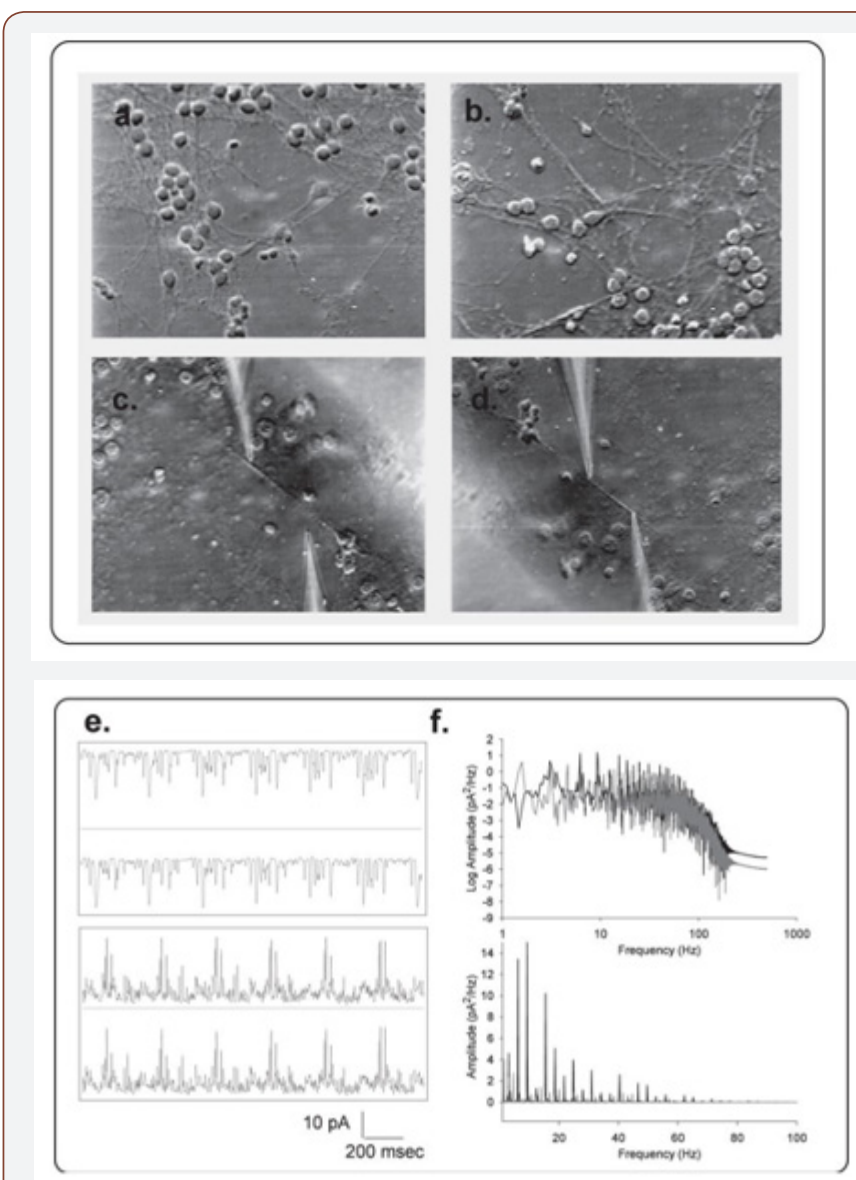

Figure 4: Consider microtubules as quantic computers that receive signals for the inside and up to $6 \mathrm{~m}$ distance from the body [6]. 


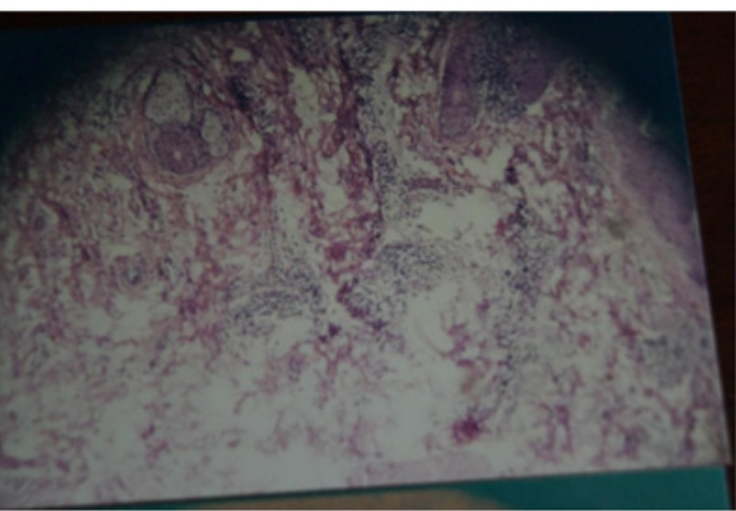

Figure 5: Destruction of fibroblasts by silicon injections. Selfproduced aggression that derives in amputation of legs, (for aesthetical purpose). Autodestructing Laboral handicaps inartists. (Pandoet. Al. coutesyphoto) Not published.

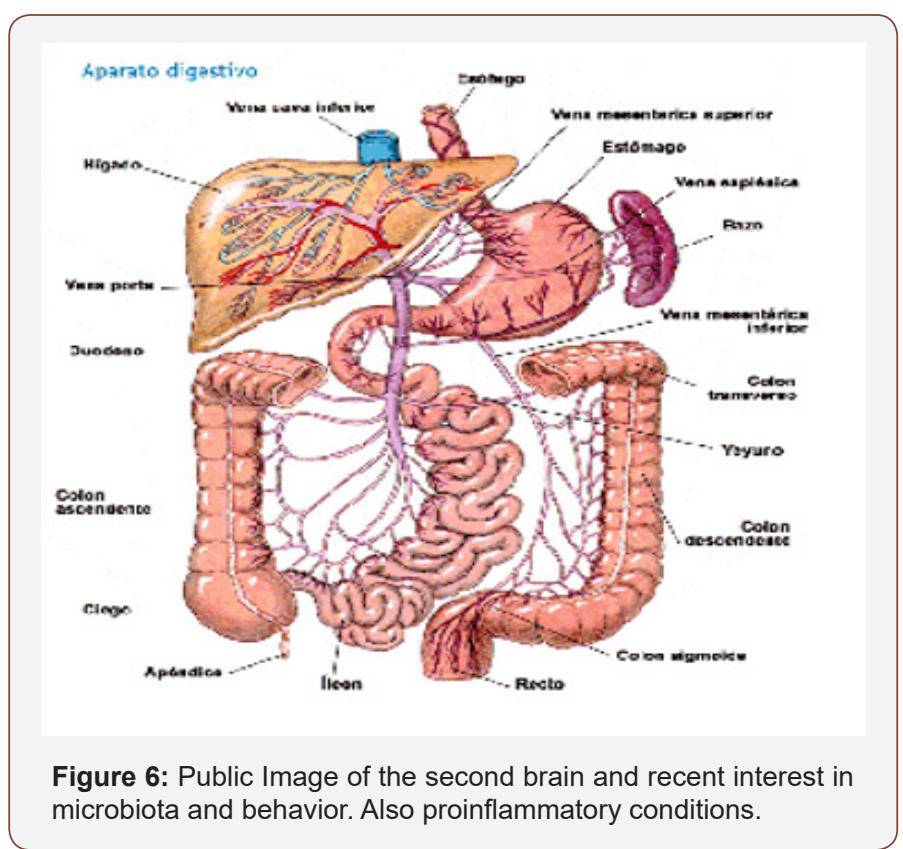

Also, with great significance in children with untreatable or refractory vomit and diarrhea that may lead to dead implicating $P$ substance or protein widely distributed in CNS and INS (Intestinal nerve system, associated to transient massive trimetilaminoaciduria. Intestinal Serotonine mediated symptom matology Vinculation to Vague nerve, thalamus and cortex, to be considered in brain damage. So Psychiatry has to evolve within the context of Neuroscience, Neuropsychiatry is not its synonimal reference, Neuropsychiatry is Neurology and Psychiatry working together in the context of Basic Science in relation to the various neural systems, all connected in our organism and this is an intended view of this complex interdisciplinary way to understand neurobiology, neuropathology, neuroclinical practice considering "all "possible interactions in health and disease and a better way of clinical practice within an enormous amount of information that each year is published including more sophisticated diagnostic and imagenological techniques that each day are perfectioned (Figure-7).

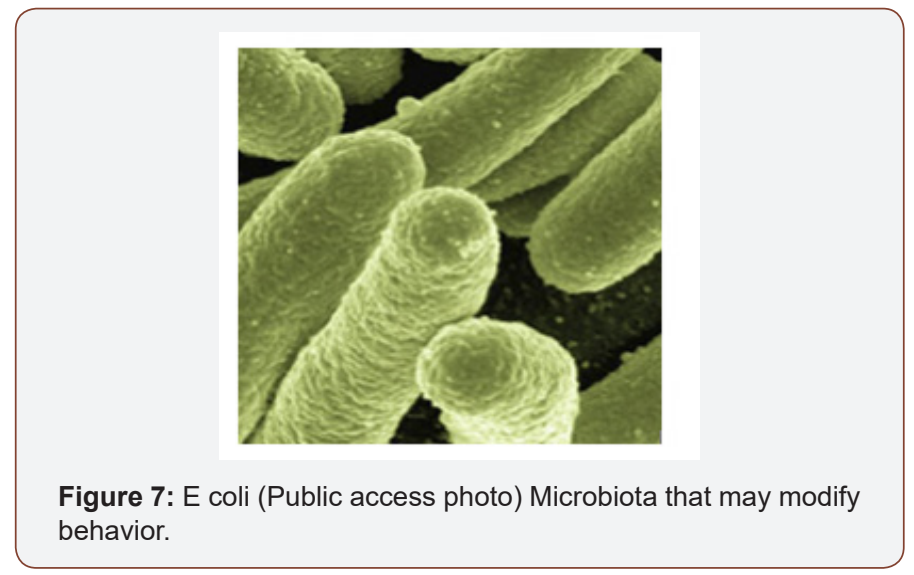

\section{Acknowledgement}

None.

\section{Conflicts of Interest}

No conflicts of interest.

\section{References}

1. K Sagan Cosmos (1980) The book and series: 1980, Random House USA.

2. Bronowsky J (1973) The ascent of man: a personal view 1973, BBC video, UK.

3. P Correa, J Arias R, Perez Tamayo, (1970) Pathology Textbook of pathology, Prensa Médica Mexicana pp.45-8

4. V Frankl Man (2015) In search of meaning. Spanish translation from Ger reimp. Herder Editorial Barc Introduction.

5. Weiz D, Gross ML, Pakrasi H (2017) Reactive Oxygen species leave a damage trail that reveals water channels in Photosystem II. advances Science 3(2): eaao3013.

6. María Del Rocío Cantero, Cecilia Villa Etchegoyen, Paula L Perez, Noelia Scarinci, Horacio F Cantiello (2018) Bundles of Brain Microtubules generate electrical oscillations. Scientific reports. 